\title{
Bariatric Surgery: Alternative Effective Intervention in Obesity Management
}

\author{
Sununta Youngwanichsetha* \\ Faculty of Nursing, Prince of Songkla University, Thailand
}

*Corresponding author: Sununta Youngwanichsetha, Associate Professor, Faculty of Nursing, Prince of Songkla University, Hat Yai, Songkhla, 90112, Thailand

Submission: 海 October 11, 2018; Published: 監 October 25, 2018

\section{Introduction}

Obesity is metabolic health problem among population worldwide. It is reported that $7 \%-27 \%$ of adults are obese, bodymass index is greater than $30 \mathrm{~kg} / \mathrm{m}^{2}$. Obesity leading to shorten life expectancy and poor quality of life because of development of many chronic diseases and complications, particularly diabetes, cardiovascular disease, stroke, chronic kidney disease, nonalcoholic fatty liver disease and cancer. Known risk factors related to obesity were genetic, overconsumption of unhealthy diets and lack of regular exercise. Excess taking of high calorie-diets containing sugar, high fructose corn syrup and trans-fat results in accumulation of advanced glycation end products and endothelial dysfunction. Moreover, low physical activity results in enlarge adipocyte cells, insulin resistance, elevated of plasma glucose, dyslipidemia, alteration of enteroendocrine and reproductive hormones associated with obesity complications. These epigenetic factors can be managed with modification of healthy lifestyles.

Prevention of obesity is the best way to control metabolic health problems. Prior research evidences show that healthy eating and doing recommended exercise or physical activities can achieve normal weight and good health. Examples of healthy diets include brown rice, whole grain, fish, egg, raw vegetable and fruits. FITTE recommendation for doing exercise is helpful to build muscle mass and burn excess body fat tissues. However, most of obese could not control their body weight because of lacking awareness, motivation, understanding of self-management processes and other conditions. Therefore, alternative effective intervention in obesity management is purposed.

Bariatric surgery is suggested to operate to reduce stomach size and nutrient absorption. Many approaches of bariatric surgery are recommended including adjustable gastric band, mini-gastric bypass, single anastomosis duodena-Ileal. Obese candidates for bariatric surgery are individuals with body mass index of or greater than $40 \mathrm{~kg} / \mathrm{m}^{2}$ or $35 \mathrm{~kg} / \mathrm{m}^{2}$ for whom with at least one or more obesity-related comorbidities such as uncontrolled type 2 diabetes, chronic hypertension, obstructive sleep apnea, coronary artery disease, cardiomyopathy, steatohepatitis from non-alcoholic fatty liver disease or severe osteoarthritis [1-9].
Research evidences reveal that there are many health benefits of undergoing bariatric surgery among obese that include achievement of target body weight, glucose and lipid plasma levels, delayed development of diabetes and metabolic syndrome complications. Better health outcomes and quality of life are also expected. It can be concluded that bariatric surgery is helpful medical intervention for individual with obesity who could not control dietary pattern and modify other health management strategies..

\section{References}

1. Baker C (2018) Bypassing bariatric costs and cutting rates of surgical site infection. ORNAC Journal 36(1): 35-48.

2. Barclay KS, Forwell SJ (2018) Occupational performance issues of adults seeking bariatric surgery for obesity. American Journal of Occupational Therapy 72(5): 1-10.

3. Claudio T, Luca B, Angelo DV, Fabrizio R, Andrea T, et al. (2018) Management of hyperuricemia and gout in obese patients undergoing bariatric surgery. Postgrad Med 130(6): 523-535.

4. Doris V (2018) Navigating care for the bariatric patient throughout the weight loss journey. Med Surg Nursing 27(3): 196-198.

5. Houlden RL, Yen JL, Moore S (2018) Effectiveness of an interprofessional glycemic optimization clinic on preoperative glycated hemoglobin levels for adult patients with type 2 diabetes undergoing bariatric surgery. Canadian Journal of Diabetes 42(5): 514-519.

6. Janse VV, Esben S, White KM, Lockie PD (2018) Psychosocial presentation of female bariatric surgery patient after multiple revisional surgeries: A qualitative study. J Health Psychol 23(10): 1261-1272.

7. Lynch AI, McGowan E, Zalesin KC (2018) Take me through the history of your weight: Using qualitative interviews to create personalized weight trajectories to understand the development of obesity in patients preparing for bariatric surgery. J Acad Nutr Diet 118(9): 1644-1654.

8. Mehran A, Rodrigo L, Ruth B (2018) A landscape of bariatric surgery in Canada: For the treatment of obesity, type 2 diabetes and other comorbidities in adults. Can J Diabetes 42(5): 560-567.

9. Raquel SS, Padin EM, Adam D, Borisenko O, Fernandez SE, et al. (2018) Bariatric surgery versus conservative management for morbidity obese patient in Spain: A cost-effectiveness analysis. Expert Rev Pharmacoecon Outcomes Res 18(3): 305-314. 
Creative Commons Attribution 4.0 International License

For possible submissions Click Here

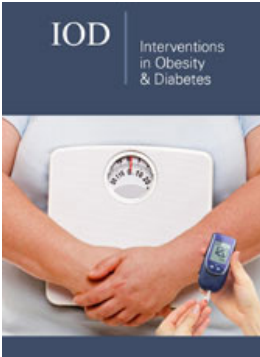

\section{Intervention in Obesity \& Diabetes}

\section{Benefits of Publishing with us}

- High-level peer review and editorial services

- Freely accessible online immediately upon publication

- Authors retain the copyright to their work

- Licensing it under a Creative Commons license

- Visibility through different online platforms 